\title{
Design, Synthesis, Chemistry and Biological Evaluation of Some Polyfunctional Heterocyclic Nitrogen Systems-Overview
}

\author{
Asmaa L. Alanzy1,2*, Dina A. Bakhotma1, Reda M. Abdel-Rahman1 \\ ${ }^{1}$ Department of Chemistry, Faculty of Science, King Abdulaziz University, Jeddah, KSA \\ ${ }^{2}$ Department of Chemistry, Faculty of Science, Qassim University, Buraidah, KSA \\ Email: ^alanzy@qu.edu.sa, ^chem.hetero@gmail.com,dbakhotmah@kau.edu.sa,rm_rahmann1951@yahoo.com
}

How to cite this paper: Alanzy, A.L., Bakhotma, D.A. and Abdel-Rahman, R.M. (2020) Design, Synthesis, Chemistry and Biological Evaluation of Some Polyfunctional Heterocyclic Nitrogen Systems-Overview. International Journal of Organic Chemistry, $10,39-62$.

https://doi.org/10.4236/ijoc.2020.102003

Received: March 24, 2020

Accepted: April 27, 2020

Published: April 30, 2020

Copyright $\odot 2020$ by author(s) and Scientific Research Publishing Inc. This work is licensed under the Creative Commons Attribution International License (CC BY 4.0).

http://creativecommons.org/licenses/by/4.0/

\begin{abstract}
The synthesis, preparation, chemical reactivities and biological activity of simple heterocyclic and heteropolycyclic nitrogen systems as small units as functional pyrazoles, pyridine and pyrimidine, and the related fused systems are reviewed. Among the various possible routes to the formation, isomeric structures have been cited because of patented reaching advanced phases of clinical trials, from 2000 to 2020 .
\end{abstract}

\section{Graph Abstract}

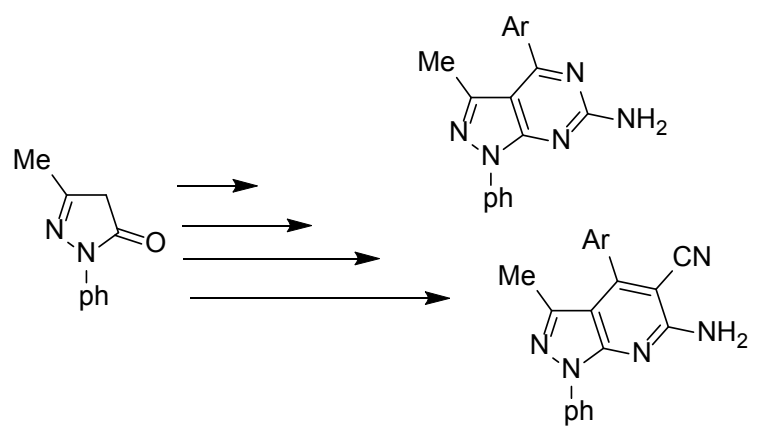<smiles>CC1=Nc2c(C)c(C#N)n(C)c(=O)c2N([I-])C1c1ccccc1</smiles>

Some compounds evaluated as antimicrobial agents 


\section{Keywords}

Pyrazolo[3,4-b]pyridine, Simple Heterocyclic Nitrogen, Biological Properties, Edaravone Drug, Synthetic Strategies

\section{Introduction}

Recently, heterocyclic nitrogen systems containing polyfunctional groups have developed into the most active and promising research areas of chemical science. Presence of polyfunctional organizations internal the structure of heterocyclic nitrogen systems, increase of net electronegativities over all the amenities of the compounds which adorn and enhance their physical, chemical and biochemical residences as dielectric content, distribution probes and/or the hydrophobic action [1].

The World Health Organization titled a recent study on the synthesis, chemical reactivity and biological activities of Polyfunctional Heterocyclic Nitrogen Systems [2] [3] [4] [5] [6].

One of the important targets is to use as antibiotics, drugs, and bioactive systems, polyfunctional pyrazoles, pyridine, and then fused/condensed polyheterocyclic nitrogen systems [7] [8] [9] [10].

\section{Synthesis and Chemical Reactivities of a Polyfunctional Pyrazole [Edaravone Drug] as Base Unties}

Edaravone drug and their analogs synthesized from the fusion of arylhydrazine with ethyl acetoacetate (Scheme 1) [11] [12].

Edaravone (1) for example exhibits two functional groups, active methylene, ketonic and/or enolic as tautomeric start [13] [14] (Figure 1)

Abdel-Rahman et al. [15] reported the synthesis of condensed heteropolycyclic nitrogen systems derived from the Edaravone drug (Scheme 2).

Fluoroacylation and/or fluorobenzoylation of Edaravone 1 an afforded 4-trifluoroacetyl-4,5-dihydro-3-methyl-1-phenylpyrazol-5-one (2) and/or 4-(4'fluorobenzoyl)-hydro-3-methyl-1-phenylpyrazol-5-one (3) respectively. Ring closure reaction of both 2 and 3 with thiourea afforded the pyrazolopyrimidine-6-thiones 4 and 5 respectively (Scheme 2) [15].

A simple nucleophilic attack of -SH groups of $\mathbf{4}$ and $\mathbf{5}$ with primary aliphatic amine as ethanolamine in refluxing $\mathrm{EtOH}$, produced the corresponds $\mathrm{N}$-substituted ethanol amines 6 and 7, which upon dehydration by refluxing with $\mathrm{Ac}_{2} \mathrm{O}$ yielded 7,8-tetrahydro-[4,3:6,5]imidazolines 8 and 9 respectively (Scheme 3) [15].

Also, the interaction between compounds 4 and 5 with primary aromatic amines in refluxing DMF afforded $\mathrm{N}$-aryl-N-pyrazolopyrimidine amines 10 and 11 respectively (Scheme 4), while when using piperazine as the secondary amine in boiling EtOH, produced $\mathrm{N}, \mathrm{N}$-di hetero arylpiperazines 12 and 13 respectively (Scheme 5) [4].

All the compounds obtained evaluated as antifungal agents, where the activity 




Scheme 1. Synthesis of edaravone drug and their analogies.

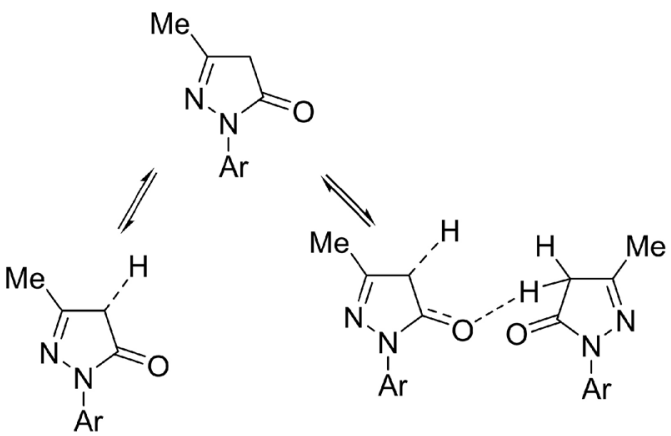

$$
A r=1-a
$$

Figure 1. Formation of edaravone 1 as two isomers.



Scheme 2. Fluoroacylation and fluorobenzoylation of edaravone 1.

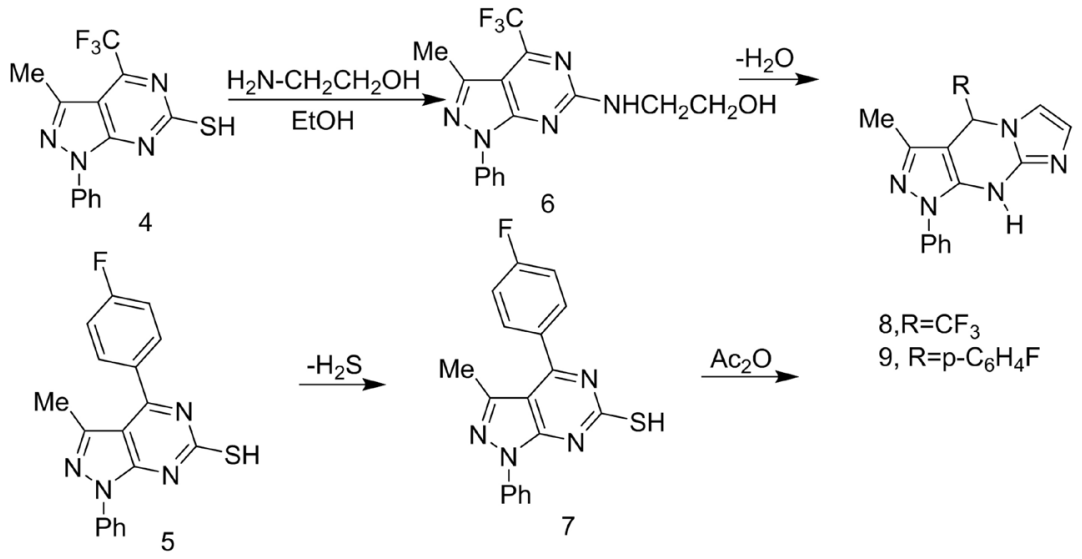

Scheme 3. Synthesis of imidazolines 8 - 9. 


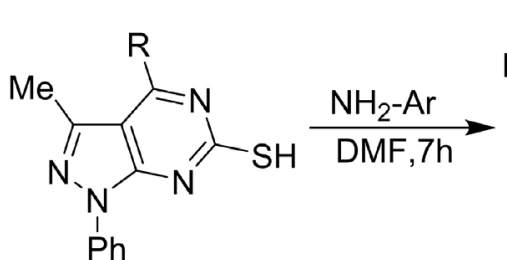

4 and 5<smiles>[R]c1nc(N[Ga])nc2c1c(C)nn2-c1ccccc1</smiles>

10 and 11

$$
\mathrm{R}=(\mathrm{a}) \mathrm{CF}_{3},(\mathrm{~b}) \mathrm{p}-\mathrm{C}_{6} \mathrm{H}_{4} \mathrm{~F} \quad \mathrm{Ar}=\mathrm{p}-\mathrm{C}_{6} \mathrm{H}_{4}-\mathrm{SO}_{2} \mathrm{NH}_{2}
$$

Scheme 4. Formation of compounds 10 - 11 from 4 - 5.<smiles>[R]c1nc(S)nc2c1c(C)nn2-c1ccccc1</smiles>

4 and 5<smiles>[R]c1nc(N2CCN(c3nc([R])c4c(C)nn(-c5ccccc5)c4n3)CC2)nc2c1c(C)nn2-c1ccccc1</smiles>

12 and 13

$\mathrm{R}=(\mathrm{a}) \mathrm{CF}_{3},(\mathrm{~b}) \mathrm{p}-\mathrm{C}_{6} \mathrm{H}_{4} \mathrm{~F}$

Scheme 5. Formation of 12 - 13 from 4 - 5.

in the order $12>10 \mathrm{a}>10 \mathrm{~b}>4>6>8$. Only compound 12 exhibits a highly affect a cellobiose activity produced by Aspergillus Nodulins Fungi at 1000 and $100 \mu \mathrm{g} / \mathrm{ml}$ as biodynamic agent [15].

The hydrazino-groups when bonded to heterocyclic nitrogen systems, improve that possible activity to formation various heteropolycyclic systems characterized with biological, pharmacological and medicinal properties [16] [17] [18]. Thus, hydrazinolysis of compound 5 by refluxing with hydrazine hydrate in $\mathrm{EtOH}$, yielded the corresponding hydrazine derivative 14 [19]. Ring closure reactions of compound 14 by refluxing with T.O.F (DMF); diethyl carbonate (THF) and/or carbon disulfide (DMF), produced the 1,2,4-triazolo pyrimido pyrazole derivatives 15 - 17 (Scheme 6) [20].

Fused heteropolycyclic nitrogen systems 19 and 20 obtained from refluxing compound 5 with benzoic acid hydrazide (DMF) and/or isonicotinic acid hydrazide (EtOH) (Scheme 7) [20].

On the other hand, the interaction between compound 5 with dithioic formic acid hydrazide in refluxing DMF led to the direct formation of compound 17 (Scheme 8) [20].

It is known that hydrazo and azo aromatic compounds exhibit an important in dust rate ant attention due to its application in the industrial chemistry and agriculture fields [21] [22]. Thus, the interaction between compound 5 and 14 (1:1 by moles) in refluxing isopropyl alcohol, the hydrazo-compound 21 , which upon simple oxidation by warming with sulfur-in dry $\mathrm{C}_{6} \mathrm{H}_{6}$, yielded the azo-compound 22 (Scheme 9) [20].

All the obtained compounds, evaluated as enzymatic affects the cellobiose activity of Aspergillus Nodulins fungi, were the activity increases in the order of 

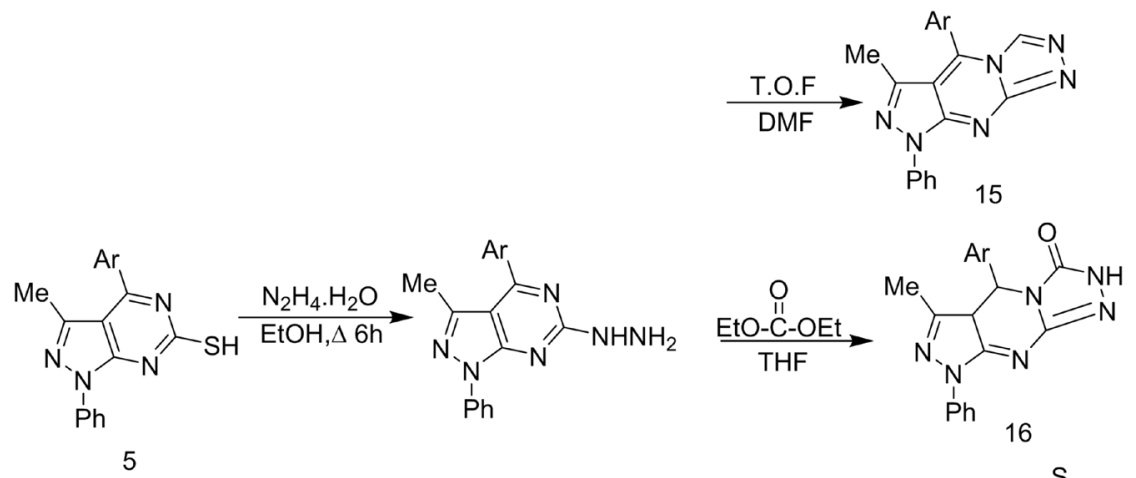

$\mathrm{Ar}=\mathrm{p}-\mathrm{C}_{6} \mathrm{H}_{4} \mathrm{~F}$

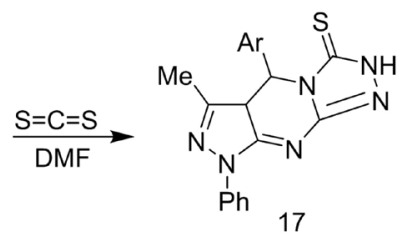

Scheme 6. Formation of 1,2,4-triazolo pyrimido pyrazole derivatives 15 - 17 .<smiles>Cc1nn(-c2ccccc2)c2nc(S)nc([Al])c12</smiles>

Ph<smiles>Cc1nn(-c2ccccc2)c2nc(=S)[nH]c(Br)c12</smiles>

5
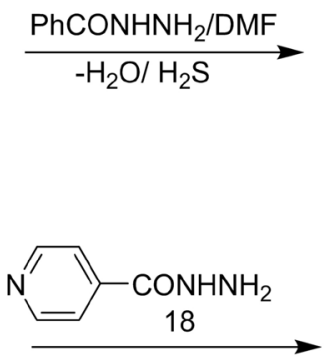

$\mathrm{Ar}=\mathrm{p}-\mathrm{C}_{6} \mathrm{H}_{4} \mathrm{~F}$<smiles>Cc1nn(-c2ccccc2)c2nc3nnc(-c4ccccc4)n3c(Br)c12</smiles>

19<smiles>Cc1nn(-c2ccccc2)c2nc3nnc(-c4ccncc4)n3c(Br)c12</smiles>

20

Scheme 7. Formation of compounds 19 - 20 from 5.<smiles>Cc1nn(-c2ccccc2)c2nc(S)nc(Br)c12</smiles><smiles>CC(=S)NNc1nc(Br)c2c(C)nn(-c3ccccc3)c2n1</smiles>

$\mathrm{Ar}=\mathrm{p}-\mathrm{C}_{6} \mathrm{H}_{4} \mathrm{~F}$<smiles>Cc1nn(-c2ccccc2)c2nc3n[nH]c(=S)n3c([Al])c12</smiles>

17

Scheme 8. Formation of compound 17 from 5. 


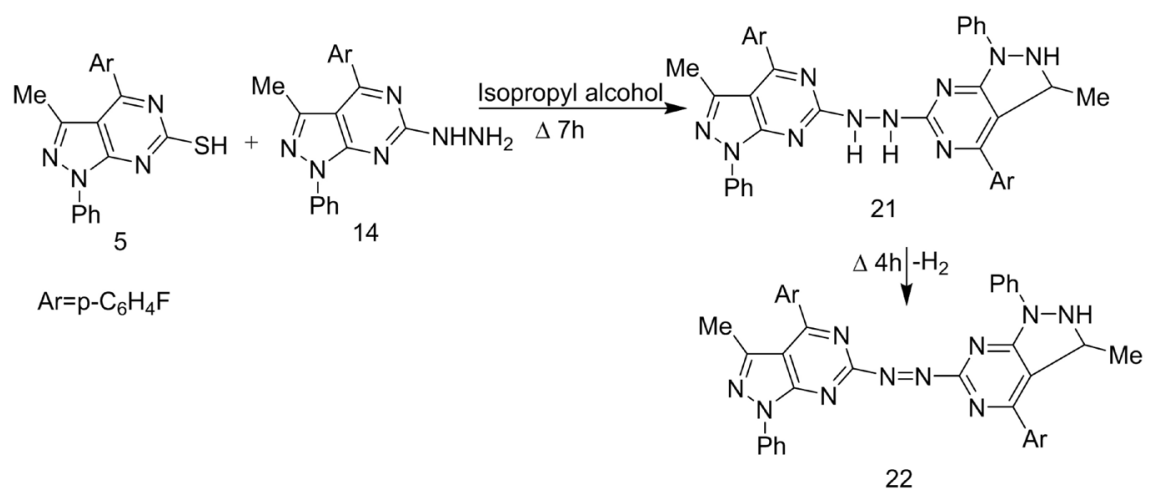

Scheme 9. Formation of azo-compound 22.

$22>21>14>16>19$ and a highly bioactive are compounds 22 and 21 Respectively [20].

Polyfunctional nitrogen compounds substituted guanidine 25, obtained from the condensation of Edaravone 1 with an aromatic aldehyde in warming with $\mathrm{EtOH} /$ piperidine produced the 5-arylidine derivative 23 which upon cycloaddition with guanidine.

$\mathrm{HCl}$ in refluxing EtOH-piperidine, yielded 6-amino-4-(4'-fluorophenyl)-1phenyl-3-methyl pyrazolo [3,4-d] pyrimidine (24). The addition of cyanamide to 24 in refluxing ethanol-piperidine, yielded the compound 25 (Scheme 10) [23].

The course of orientation cyclization reactions, is very important to obtain a type of isomeric structure [24]. Thus, refluxing compound 25 with 4-nitrobenzoyl isothiocyanate in non-polar solvent (dioxane) gave 1-heteroaryl-2-imino-6-aryl1,3,5-triazin-6 $(5 \mathrm{H})$ thione (26), while that reaction when carried in polar solvent (EtOH/pipridine) produced1-heteroaryl-2-imino-4-aryl-1,3,5-triazin-6 $(5 \mathrm{H})$ thione (27) respectively (Scheme 11) [23].

It is an interest that interaction between compound 25 as polynuclophilic agents with $\pi$-e acceptors bearing a carbon triple group as unsaturated carbonitriles (A) and/or (B) in polar solvent as EtOH/piperidine as catalyst led to the direct formation of polyfunctional hetero polycyclic systems 28 and 29 respectively (Scheme 12) [23].

Also, cycloaddition reaction of compound 25 with 1-phenyl-3-methyl-4arylidene-pyrazol-5-one (23) in refluxing EtOH-piperidine afforded the diheteroarylamine derivative 30 (Scheme 13) [23].

Recently, reported that [25]-[30], the introduction of fluorine atoms to heterocyclic nitrogen systems often improves then physical, chemical and biological properties [25]-[30]. Thus, cyclo condensation of compound 25 with fluorinated acetylacetone in refluxing EtOH, afforded N-(heteroaryl-2-imino-4,6-di(trifluoromethyl) pyrimidine (31) (Scheme 14 \& Scheme 15) [23].

Some full fused heteropolycyclic nitrogen systems bearing various functional groups 32 - 39 were obtained from the interaction between 6-amino-4-(4'-fluorophenyl)-1-phenyl-3-methyl pyrazolo [3,4-d]pyrimidine (24) 23, with $\alpha$, $\beta$-bifunctional reagents via a ring closure reaction (heterocization systems) [31]. 


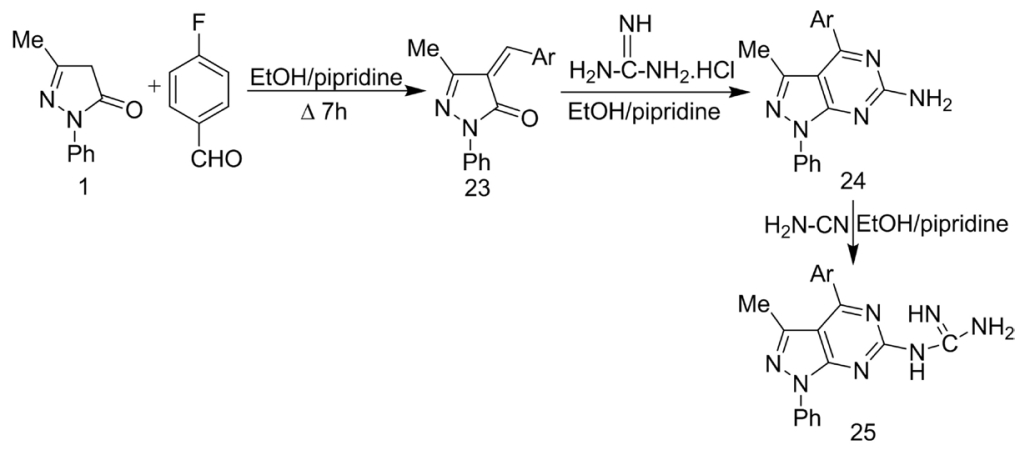

Scheme 10. Synthesis of pyrazolo[3,4-d]pyrimidine 25 .

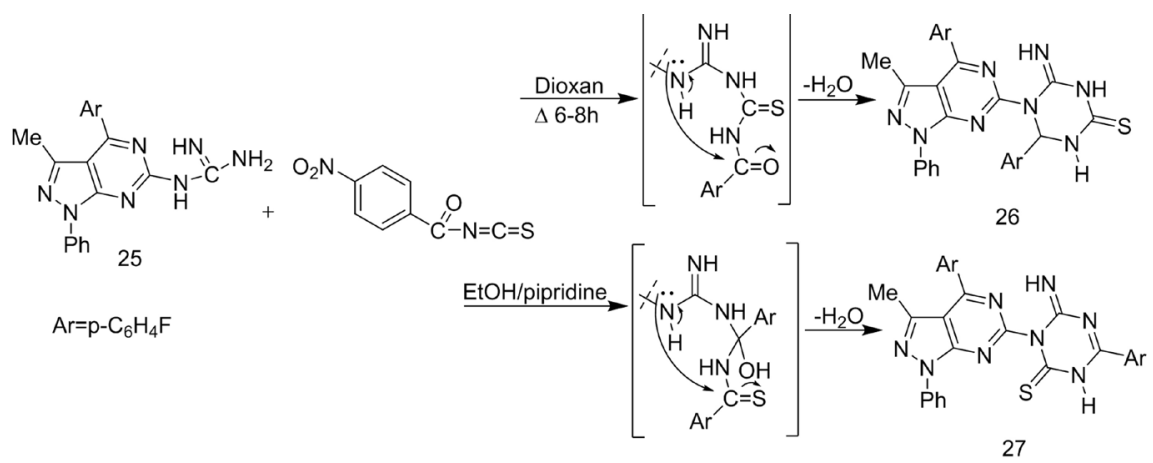

Scheme 11. Synthesis of 1,3,5-triazin 6(5H)thione derivatives 26 - 27.

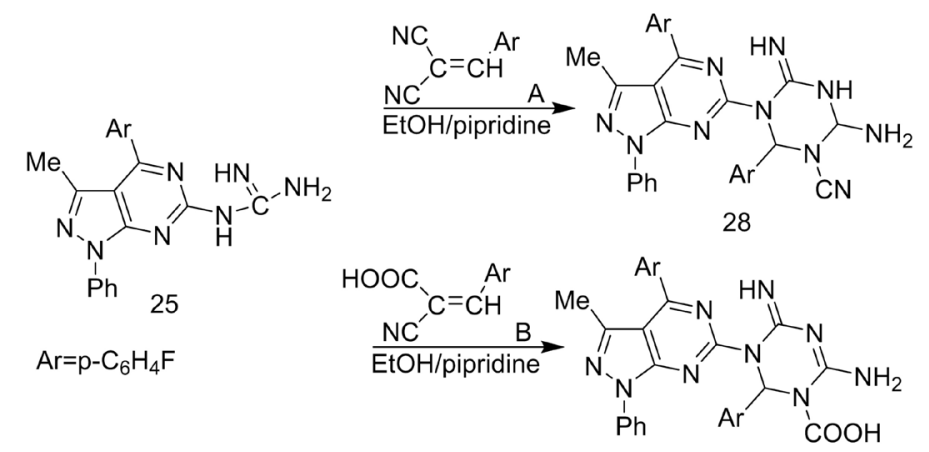

29

Scheme 12. Formation of 28 - 29 from 25.

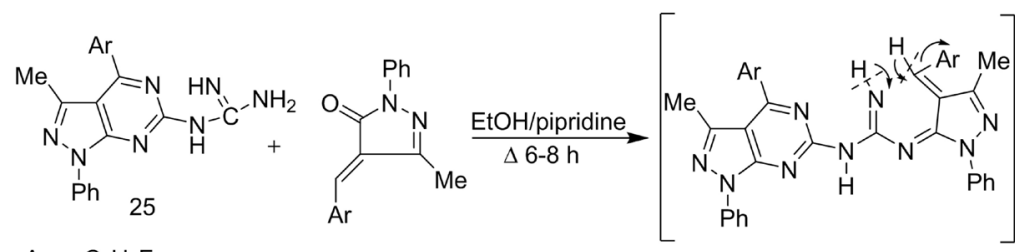

$\mathrm{Ar}=\mathrm{p}-\mathrm{C}_{6} \mathrm{H}_{4} \mathrm{~F}$

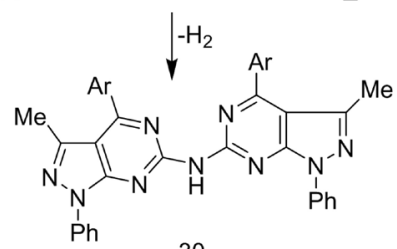

Scheme 13. Synthesis of dihetero aryl amine derivative $\mathbf{3 0 .}$ 


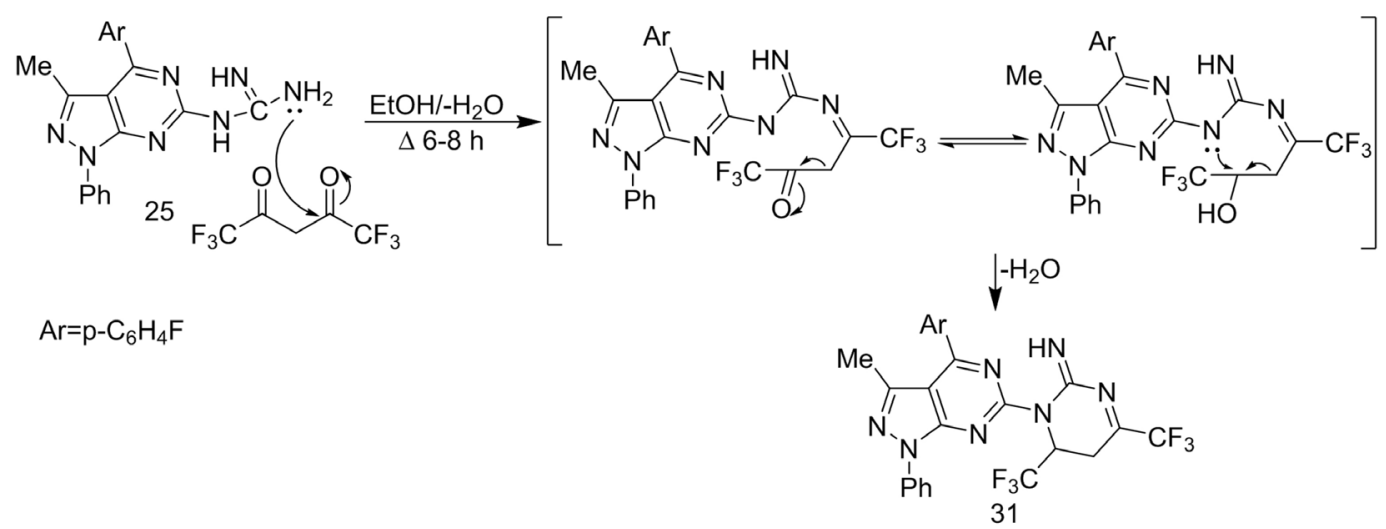

Scheme 14. Formation 31 from 25.

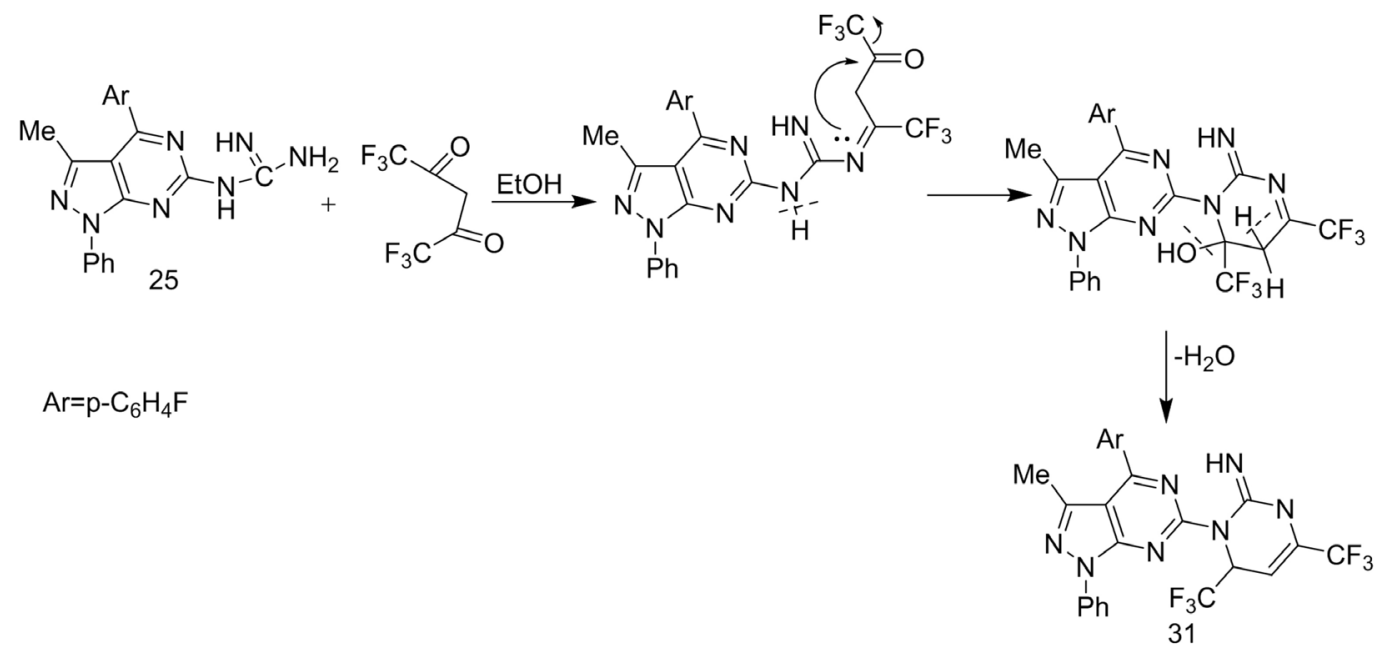

Scheme 15. Formation of $\mathbf{3 1}$ from 25.

Thus, refluxing of compound $\mathbf{2 4}$ with chloroacetonitrile and/or monochloroacetic acid in boiling DMF for $4 \mathrm{~h}$, yielded the imidazo [3,2-a]pyrimido [4,3-d]pyrazoles 32 and 33 respectively (Scheme 16) [31].

The interaction between compound $\mathbf{2 4}$ and the active methylene reagents as malononitrile (EtOH/piperidine) and/or diethyl malonate (THF) under refluxing $\Delta / 6 \mathrm{~h}$, resulted in pyrimido [3,1-a]pyrimido [5,4-d]pyrazole (34 and 35) respectively (Scheme 17) [31].

The behaviour of compounds $\mathbf{3 2}$ and $\mathbf{3 5}$ as nucleophilic agents towards $\mathrm{Pph}_{3}$ as electrophilic agents also evaluated in boiling $\mathrm{CH}_{3} \mathrm{CN}$, led to the direct formation of triphenylphosphine derivatives imino 36 and 37 respectively (Scheme 18) [31]. Formation of compound 36 as shown in Figure 2.

On other hand, refluxing compound 24 with 4-nitrobenzoyl isothiocyanate in non-polar solvent (dioxane or THF) and/or in polar solvent (EtOH/piperidine) also, afforded 2-aryl-4-thioxo-6-(4'-fluorophenyl)-7-methyl-9-phenyl-1,3,5-triazino [5,4-a]pyrimido[5,4-d]pyrazole (38) and/or 2-thioxo-4-(aryl)-6-(4'-flourophenyl7-methyl-9-phenyl-1,3,5-triazino[5,4-a]pyrimido[5,4-d]pyrazole (39) respectively (Scheme 19) [31]. 
<smiles>Cc1nn(-c2ccccc2)c2nc(N)nc(Br)c12</smiles>

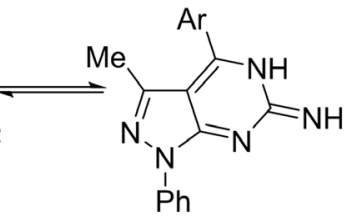
24

$\mathrm{Ar}=\mathrm{p}-\mathrm{C}_{6} \mathrm{H}_{4} \mathrm{~F}$<smiles>Cc1nn(-c2ccccc2)c2nc3ncc(N)n3c([141I])c12</smiles><smiles>Cc1nn(-c2ccccc2)c2nc3ncc(N)n3c([Al])c12</smiles>

Scheme 16. Synthesis of imidazo[3,2-a]pyrimido[4,3-d]pyrazoles 32 - 33.<smiles>Cc1nn(-c2ccccc2)c2nc(=N)[nH]c(Br)c12</smiles>

24

$$
\mathrm{Ar}=\mathrm{p}-\mathrm{C}_{6} \mathrm{H}_{4} \mathrm{~F}
$$

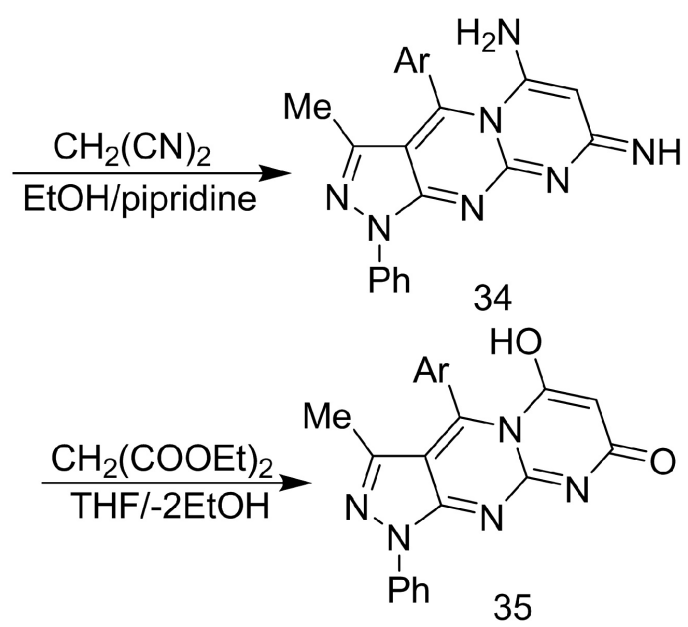

35

Scheme 17. Formation of 34 - 35 from 24.<smiles>Cc1nn(-c2ccccc2)c2nc3ncc(N)n3c([Al])c12</smiles>

32<smiles>Cc1nn(-c2ccccc2)c2nc3nc(=N)cc(N)n3c([Al])c12</smiles>

35

\section{$\mathrm{Ar}=\mathrm{p}-\mathrm{C}_{6} \mathrm{H}_{4} \mathrm{~F}$}

Scheme 18. Treatment of 35 and 32 with $\mathrm{pph}_{3}$ and $\mathrm{CH}_{3} \mathrm{CN}$. 


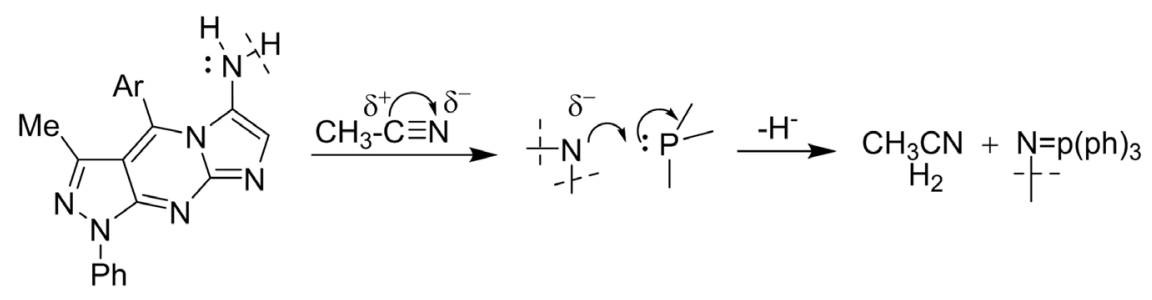

32

$\mathrm{Ar}=\mathrm{p}-\mathrm{C}_{6} \mathrm{H}_{4} \mathrm{~F}$

Figure 2. Formation of phosphinimino 36.<smiles>COc1nn(-c2ccccc2)c2nc3nc(=S)nc(Br)n3c(=S)nc12</smiles>

Scheme 19. Formation of 38 - 39 from 24.

\section{Synthesis and Chemical Reactivities of a Polyfunctional Pyridine Systems (1,6-Diamino-2-oxo-4-(aryl)- 1,2-dihydropyridine-3,5-dicarbonitrile)}

A general method to obtain 4-aryl-1,6-diamino-2-oxo-1,2-dihydropyridine-3,5dicarbonitriles 40 includes the interaction between cyanoacetic acid hydrazide, malononitrile and aromatic aldehyde in refluxing absolute $\mathrm{EtOH}$ with drops of piperidine (Scheme 20) [32].

Abdel-Monem [33] reported the synthesis of fused heterobicyclic nitrogen systems as 1,2,4-triazolopyridinone $\mathbf{4 1}$ - $\mathbf{5 0}$ derived from compounds $\mathbf{4 0} \mathbf{a}_{\mathrm{a}}$ and $40_{\mathrm{b}}$ with $\alpha, \beta$-bifluorodional oxygen and halo-oxo compounds in different media (Scheme $21 \&$ Scheme 22). Also, fused pyrido-1,2,4-triazine 53 - 60 have been obtained from treatment of 3-mercapto-5,6-diphenyl-1,2,4-triazine 51 with compound 40 to give the substituted aminopyridinone 52 (Scheme $21 \&$ Scheme 22) [33].

It is the interest that, compound $\mathbf{5 2}$ on alkylated and/or cyclocendened with an alkyl halide (Base) and/or hydroxy/halo ketones afforded the pyrido-1,2,4-triazine derivatives 53 - 60 (Scheme 23 \& Scheme 24) [33].

All the obtained compounds evaluated as antimicrobial agents (some Bacteria and fungi); were the compounds exhibit good to moderate activities in the order of $54,47,45$ as bactericidal and the compounds $46,50,58$ exhibit a fungicidal activity [33]. 


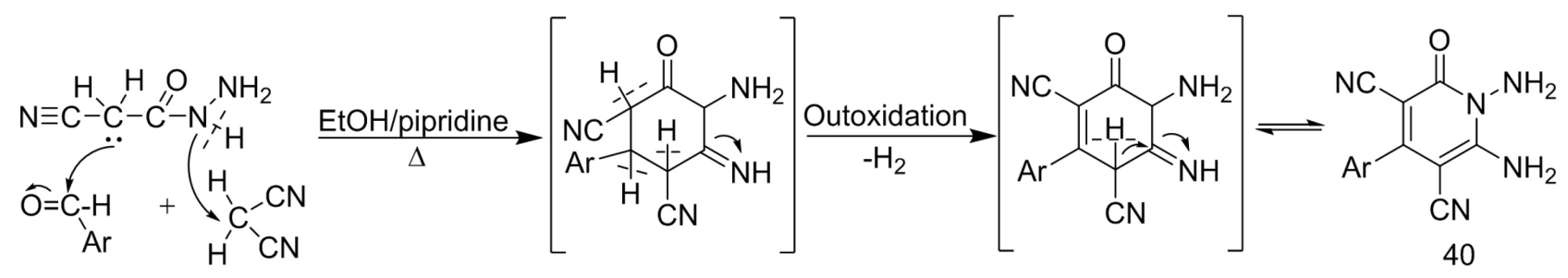

Scheme 20. Formation of pyridine derivative $\mathbf{4 0}$.

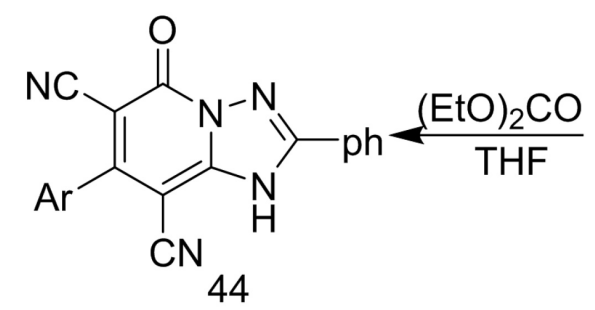<smiles>CC(O)OC(=O)/[SH]=c1\[nH]c2c(C#N)c(Br)c(C#N)c(=O)n2[nH]1</smiles><smiles>N#Cc1c(Br)c(C#N)c(=O)n(N)c1N</smiles><smiles>N#Cc1c(Br)c(C#N)c2[nH]cnn2c1=O</smiles><smiles>[AlH2]</smiles><smiles>[AsH2]</smiles><smiles>N#Cc1c([Al])c(C(N)(F)F)c(=O)n2[nH]c(=O)[nH]c12</smiles>

$\mathrm{Ar}=\mathrm{p}-\mathrm{C}_{6} \mathrm{H}_{4} \mathrm{Cl}$<smiles>Cc1nn2c(=O)c(C#N)c(Br)c(C#N)c2[nH]1</smiles>

Scheme 21. Formation of 1,2,4-triazolopyridinone 41 - 45.

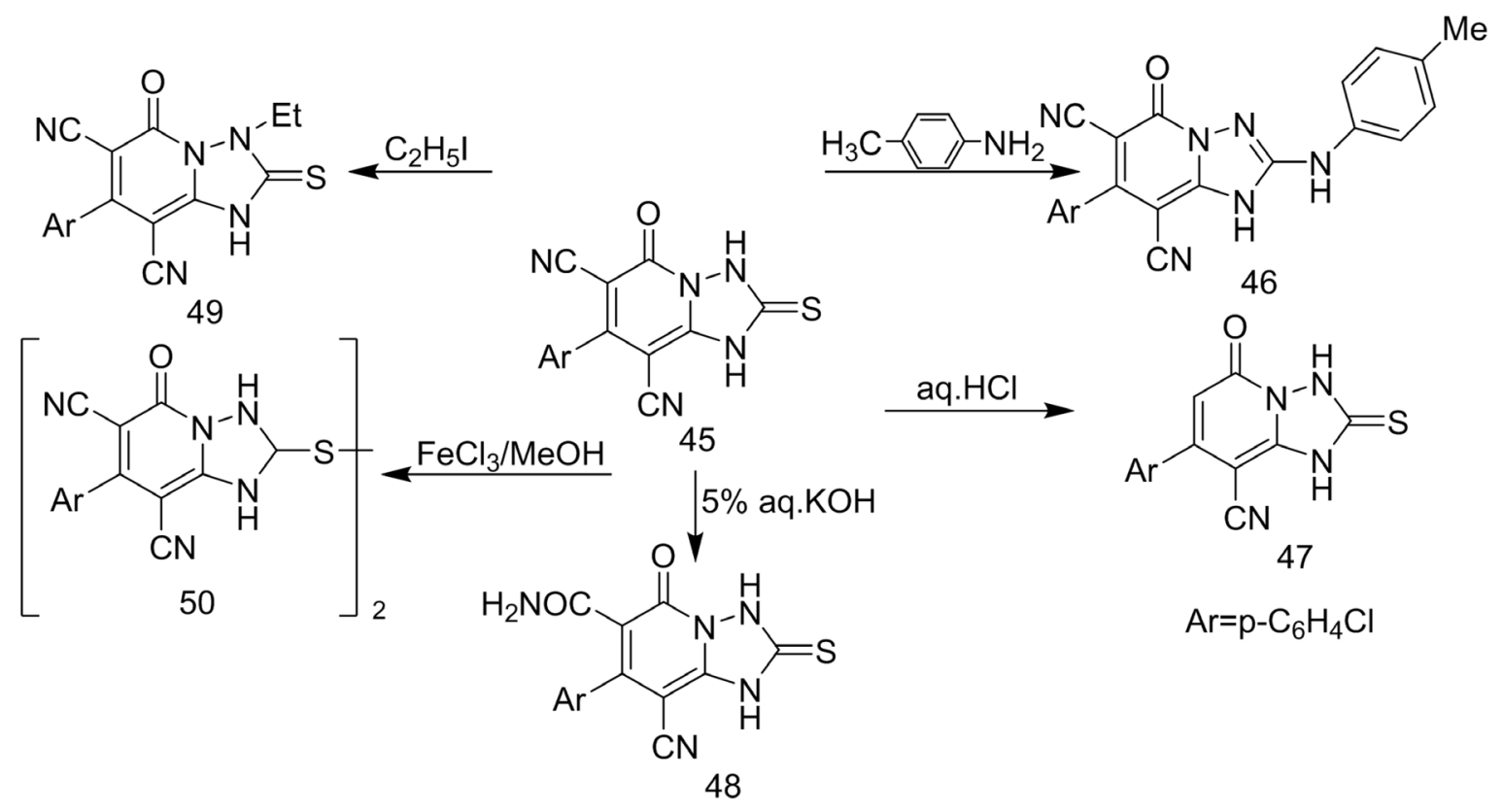

Scheme 22. Formation of 46 - 50 from 45. 


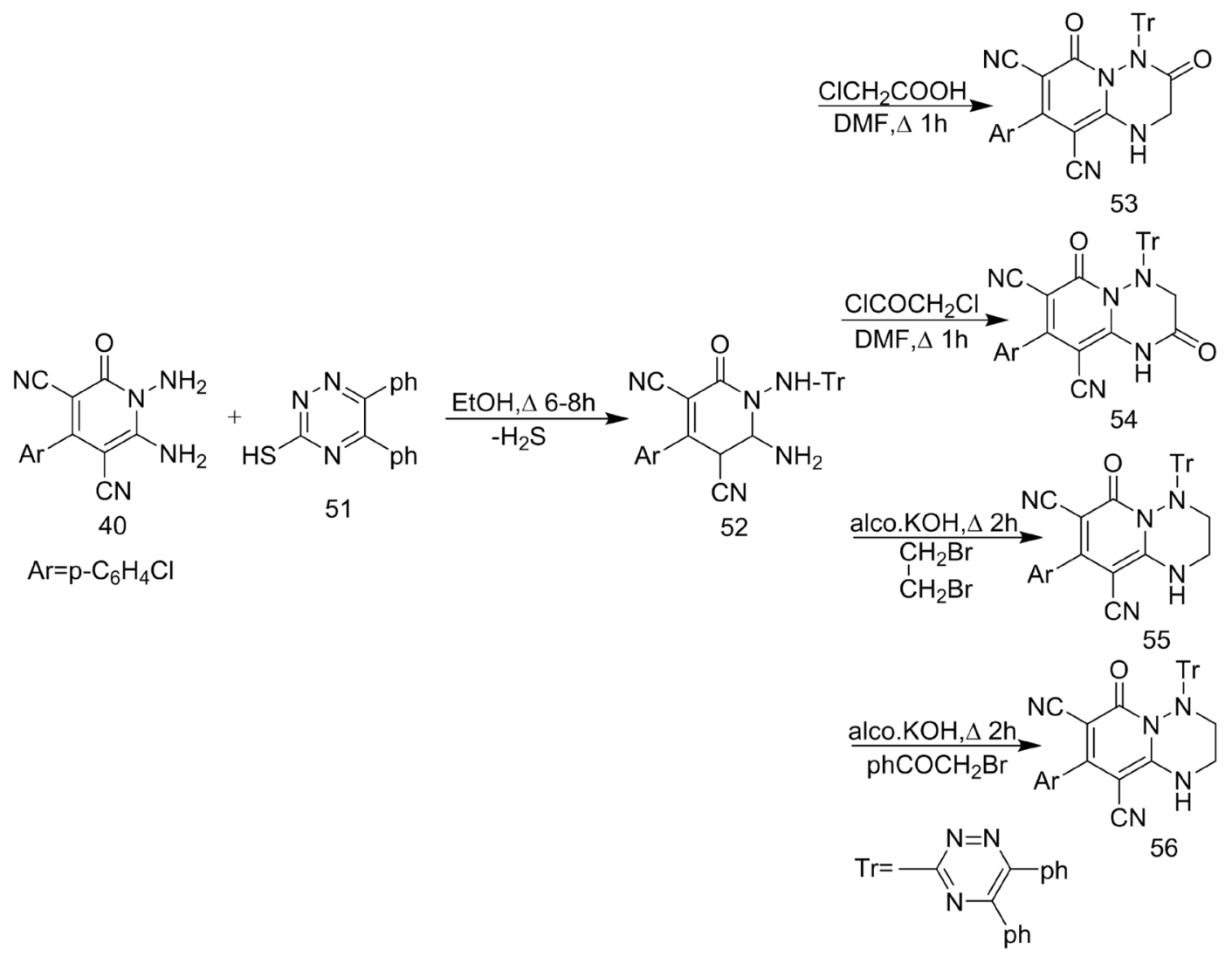

Scheme 23. Formation of 53 - 56 from 40 and 51.
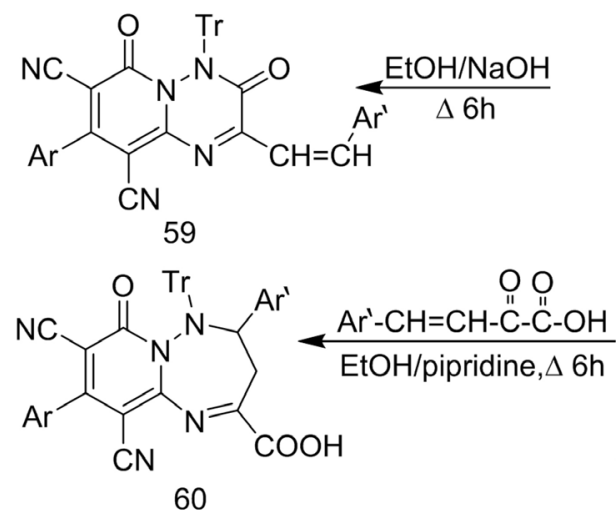<smiles>N#CC1=C(Br)C(C#N)C(N)N(N=[In])C1=O</smiles>

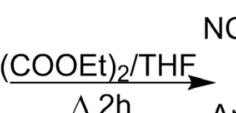<smiles></smiles>

57

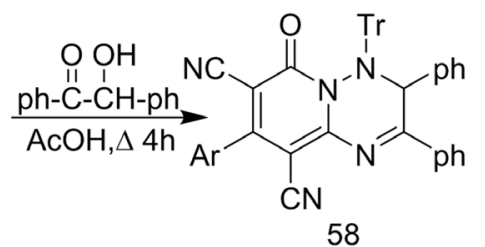

Scheme 24. Formation of 57 - 60 from 40.

Simitary [34] [35] [36], polyfunctional pyrido-1,2,4-triazine derivatives 61 65 and the related fused polyheterocyclic systems 66 and 67 were isolated from the interaction between compound 40 (Ar:-furyl) and $\alpha$, $\beta$-bifunctional reagents in the differing media (Schemes 25-27). All the obtained compounds showed antimicrobial activity (bacteria \& fungi) in comparison with chloramphenicol and terbinafine antibiotics as control [34]. The compounds $64 \& 66$ are highly active towards staphylococcus, while compounds $66 \& 68$ against Bacillus $\mathrm{S}$. 

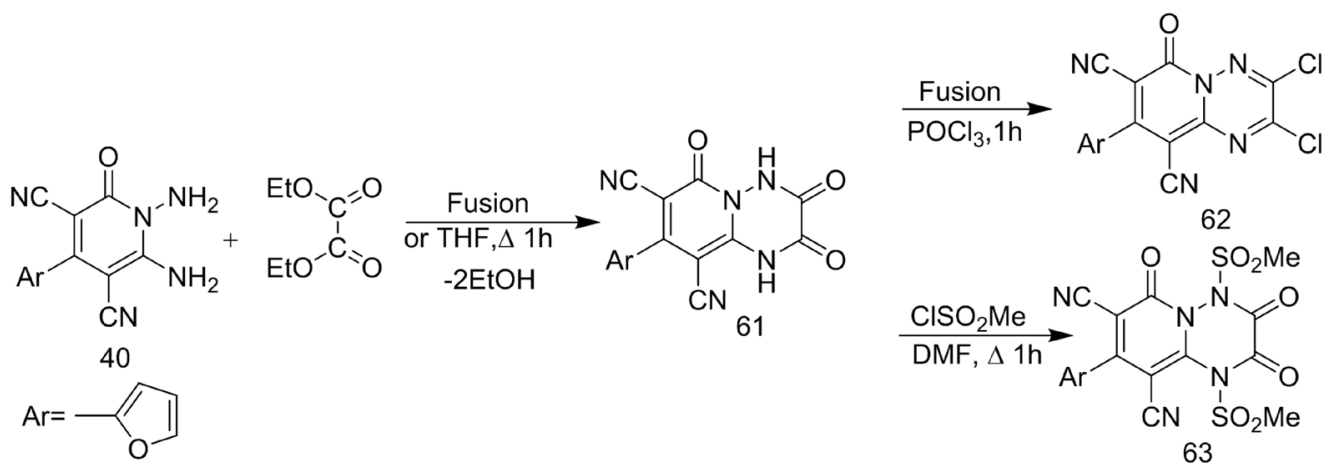

Scheme 25. Formation of 62 - 63 from 40 .<smiles>N#Cc1c([Al])c(=O)n2nc(Cl)c(Cl)nc2c1C#N</smiles>

62<smiles>[Al]c1ccco1</smiles><smiles>CN(CCCCC(C)(F)F)c1ccccc1N</smiles><smiles>N#Cc1c(N)c(N)n(N)c(=O)c1C#N</smiles><smiles>N#Cc1c(Br)c(C#N)c2nc(Nc3ccccc3N)c(Cl)nn2c1=O</smiles>
64<smiles>N#CC1=C([Al])C(N)C(=O)C(Nc2cnn3c(=O)c(C#N)c([Al])c(C#N)c3n2)C1N</smiles>

Scheme 26. Formation of 64 - 65 from 62.<smiles>N#Cc1c([Al])c(C#N)c2nc(Cl)c(Cl)nn2c1=O</smiles>

62<smiles>[Al]c1ccco1</smiles><smiles>N#Cc1c(Br)c(C#N)c2nc3c(nn2c1=O)NCCN3CCNCCN</smiles>

66<smiles>N#Cc1c([Al])c(C#N)c2nc3c(nn2c1=O)C(C#N)C(=O)NN3</smiles>

67

Scheme 27. Formation of 66 - 67 from 62 .

Most of the compounds 61 - 68 showed towards activity Staphylococcus, Bacillus S.L pseudomonas, and only the compounds 66 towards Escherich co.

On the other hand, the compound, 68 showed a high activity towards Candida albicans fungi. Also, the compounds $61 \& 66$ exhibit activity towards Aspergillus 
F.; 62, 63 \& 68 towards penicillium ita; 61 - 68 towards candida alb.

Diamines are very important and safe, active simple substrates for producing of various heterocyclic nitrogen systems [37] [38]. Also, 4-aryl-1,6-diamino-2-oxo1,2-dihydropyridine-3,5-dicarbonitriles uses for the building of high biologically active nitrogen bridgehead triazole [1,5-a]pyridines [39]; pyrido [1,2-b] $[1,2,4]$ triazines [40] [41] and/or pyrido [1,2-b] [1,2,4]triazepines [42] [43]. Based on, these observations-Kazak et al. [44] obtained 4-(4'-methoxyphenyl)-1,6diamino-2-oxo-1,2-dihydropyridine (68) from refluxing ethyl cyanoacetate, arylaldehyde, malononitrile; hydrazine hydrate in $\mathrm{EtOH}$ with a few drops of piperdine (Scheme 28) [44], and uses to obtaining various fused polyheterocyclic nitrogen systems 69 - 73 as antimicrobial agents (Schemes 28-30) [44]. All the compounds obtained evaluated as antimicrobial agents, were the highly active compounds in the order $73>72$ towards Bacillus bacterial S.L towards candida a. (fungi strain) [44].

The formation of compound 67 may be as shown in Figure 3.

Diamines are very important and safe, active simple substrates for producing of various hetero cyclic nitrogen systems [37] [38]. Also, 4-aryl-1,6-diamino-2oxo-1,2-dihydropyridine-3,5-dicarbonitriles uses for the building of high biologically active nitrogen bridgehead triazolo [1,5-a] pyridines [39]. Pyrido [1,2-b] [1,2,4]triazines [40] [41] and/orpyrido [1,2b] [1,2,4]triazepines [42] [43].

Based on, these observations, El-Kazak et al. 44 prepared 4-(4'-methoxyphenyl)1,6-diamino-2-oxo-1,2-dihydropyridine (68) from refluxing ethyl cyanoacetate, aryl aldehyde, malononitrile, hydrazine hydrate in EtOH with a few drops of piperidine (Scheme 28) [44], and uses to obtaining various fused polyheterocyclic nitrogen systems 69 - 73 as antimicrobial agents (Schemes 28-30) [44].

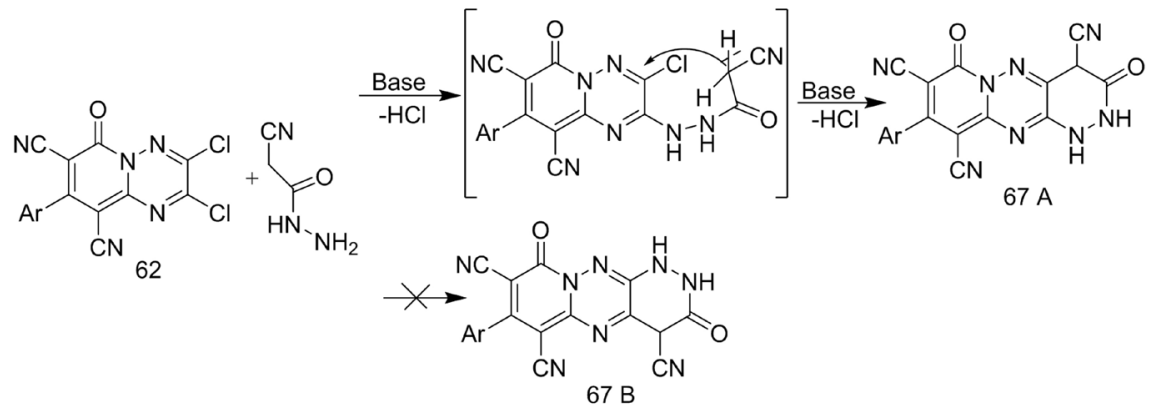

(A)

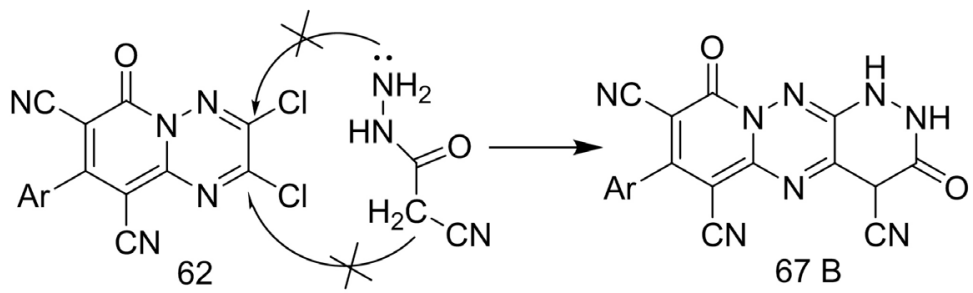

(B)

Figure 3. (A) Formation of compound 67A from 62; (B) Anot possible formation of compound 67B from 62. 


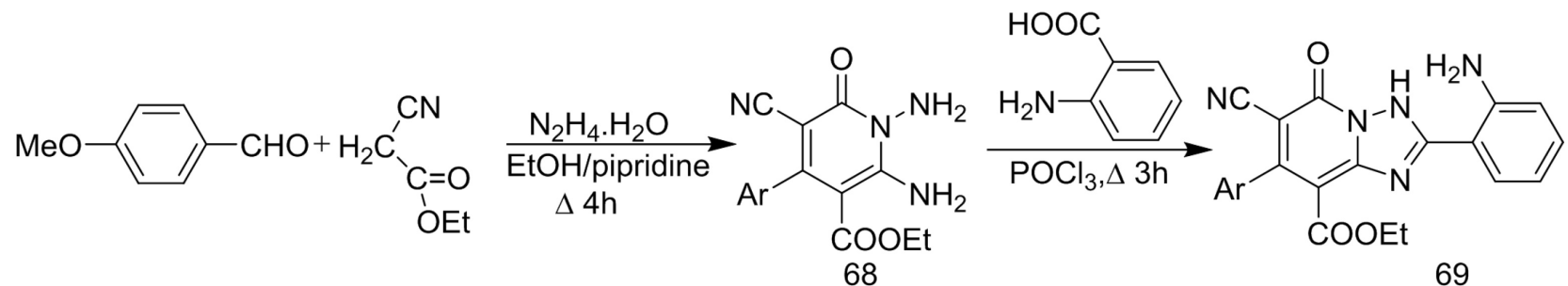

Scheme 28. Formation of 69 from 4-methoxybenzaldehyde.<smiles>CCOC(=O)c1c(Br)c(C#N)c(=O)n2[nH]c(-c3ccccc3N)nc12</smiles>

$\mathrm{Ar}=4-\mathrm{MeO}-\mathrm{C}_{6} \mathrm{H}_{4}$<smiles></smiles><smiles>CCOC(=O)c1c(Br)c(C#N)c(=O)n2c(C)nc3ccccc3c12</smiles>

71

Scheme 29. Formation of 70 - 71 from 69.<smiles>CC1=NNC(=O)C1C(=O)c1ccc(F)cc1</smiles>

3<smiles></smiles><smiles>[H][R5]([H])(OCC)N1C2=C(C(=O)OCC)C(Br)=C(C#N)C(=O)N1C(=S)Nc1ccccc12</smiles>

73

Scheme 30. Formation of $72-73$ from 3.

All the compounds obtained evaluated as antimicrobial agents, were the highly active compounds in the order $\mathbf{7 3}>\mathbf{7 2}$ towards Bacillus $s$. and towards Candida a. (fungi strain) [44].

\section{Synthesis and Chemical Reactivities of Polyfunctional Pyrazolo-Pyridine Derivatives}

Various pyrazolo[3,4-d]pyridine derivatives $\mathbf{7 6}-\mathbf{8 0}$ have been obtained from the reaction of 3-hydrazino-5,6-diphenyl-1,2,4-triazine (74) 46 with ethoxy methy- 
lene malononitrile in refluxing EtOH to give 5-amino-1-(5,6-diphenyl-1,2,4triazine-3-yl)-1H-pyrazole-4-carbonitrile (75) which used as starting materials to obtain the targets $76-\mathbf{8 0}$ (Schemes 31-33) [45].

\section{Important and Applications}

Fused heterocyclic nitrogen systems especially which containing a pyrazole moiety are well known for their wide range of biological, pharmacological and medicinal significance properties [46] [47] [48] [49] [50]. Also, pyrazolo [3,4-b]pyridines have been exhibited the diverse biological and pharmacological fields such as antitubercular, antibacterial, anti-inflammatory, antipyretic, antileishmanial and protein Kinase Potential inhibitors agents [51]-[60].

Some pyrazolo[3,4-b]pyridines have been obtained and evaluated for an anti-chagasic activity to establish a structure-activity relationship [61].

A few publications deal with the preparation of pyrazolo [3,4-b]pyridines containing a polyfunctional group [62].

In continuation of the work done on the synthesis and chemistry of pyrazolo [3,4-b]pyridines [63], Maqbool et al. 64 prepared a series of ethyl-3-methyl1-phenyl-6-aryl-1H-pyrazolo[3,4-b]pyridine-4-carboxylates (82) by the reaction of 5-amino-3-methyl-1-phenyl-1H-pyrazole (81) [64] with various aromatic aldehydes and ethyl pyruvate in warming acetic acid (Scheme 34) [65].

One of the important studies of synthesis, chemistry and biological evaluation of polyfunctional pyrazolo[3,4-b]pyridine-carbonitrile was deduced by El-Assiery et al. [66], was the compound 1-phenyl-3-methyl-4-aryl-6-amino pyrazolo [3,4-b] pyridine-5-carbonitriles (83) obtained from the cycloaddition of both Edaravone 1, aromatic aldehydes; malononitrile and ammonium acetate by fusion with a few drops of piperidine within a long time $(15 \mathrm{~h})$ (Scheme 35$)$ [66].

Also, the chemistry of compound $\mathbf{8 3}$ was studied by treatment with polyfunctional reagents, because of their biological evaluation (Scheme 36 and Scheme 37) [66].

\section{Attitudes of the Next New Work}

Based upon these observations, the next work tends to synthesize some more new fused heteropolycyclic nitrogen systems containing polyfunctional groups because of their biocidal effects.

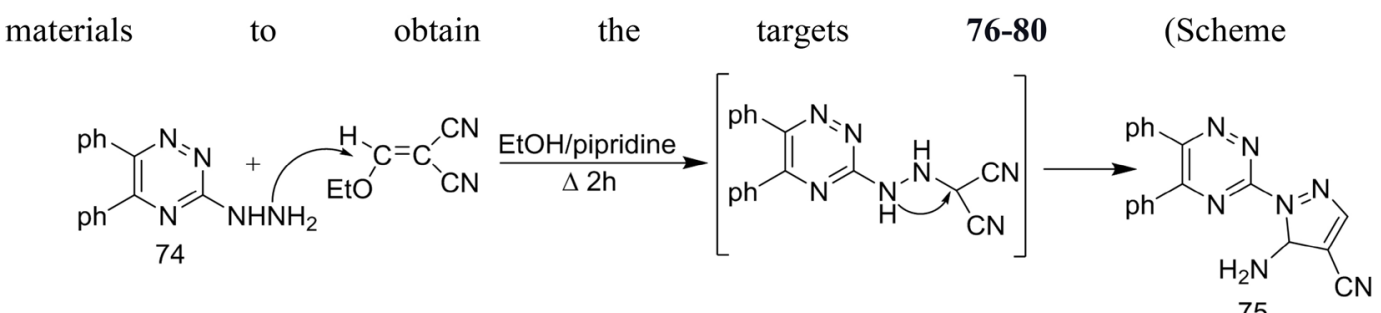

Scheme 31. Reaction of 3-hydrazinotriazine 74 with ethoxymethylene malononitrile. 


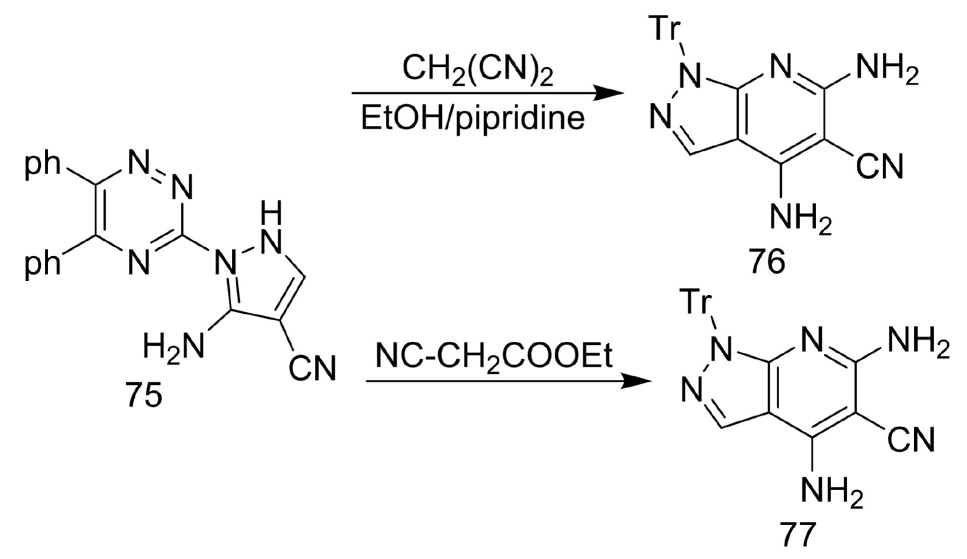

Scheme 32. Formation of $\mathbf{7 6}-\mathbf{7 7}$ from $\mathbf{7 5 .}$

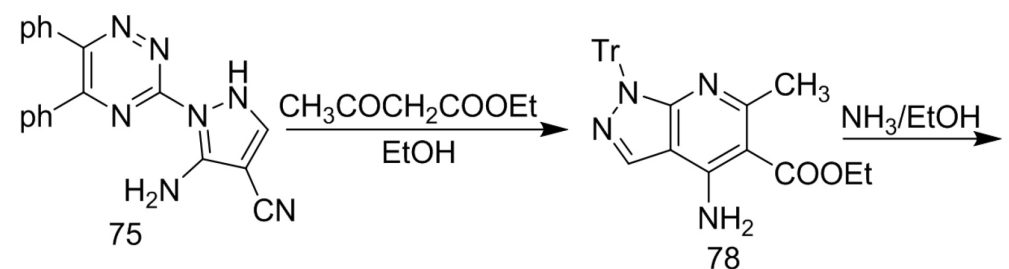<smiles>Cc1nc2c(cnn2[I-])c([N+](=O)[O-])c1C(N)=O</smiles><smiles>Cc1nc2c(cnn2[Tl])c(N)c1C#N</smiles>

Scheme 33. Synthesis of compound $\mathbf{8 0 .}$

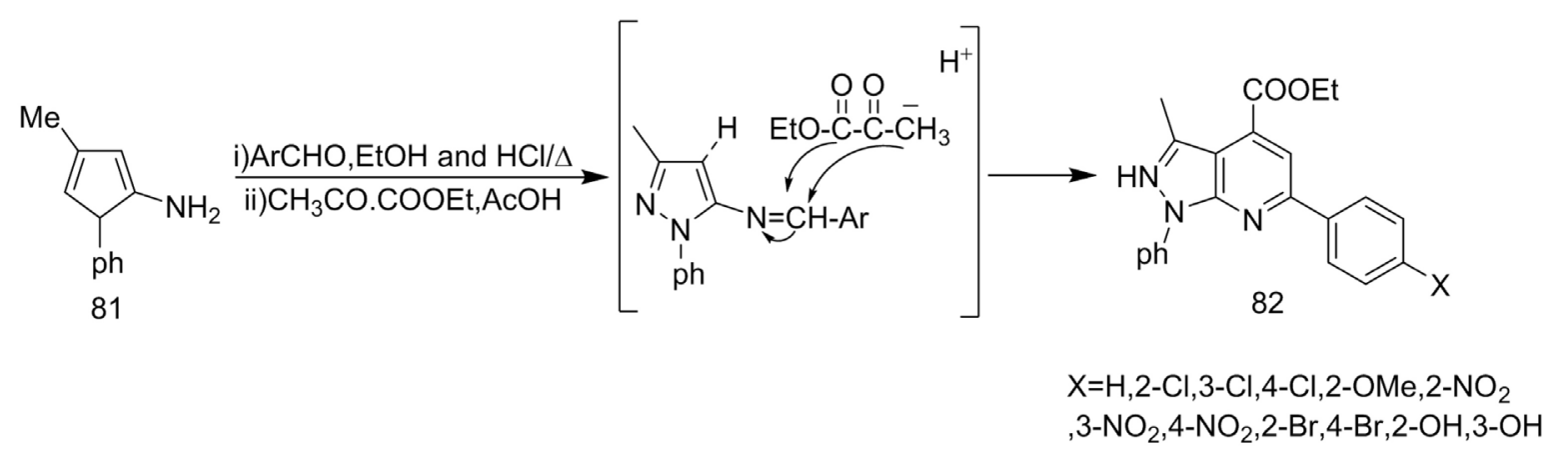

Scheme 34. Synthesis of pyrazolo[3,4-b]pyridine-4-carboxalate 82 .

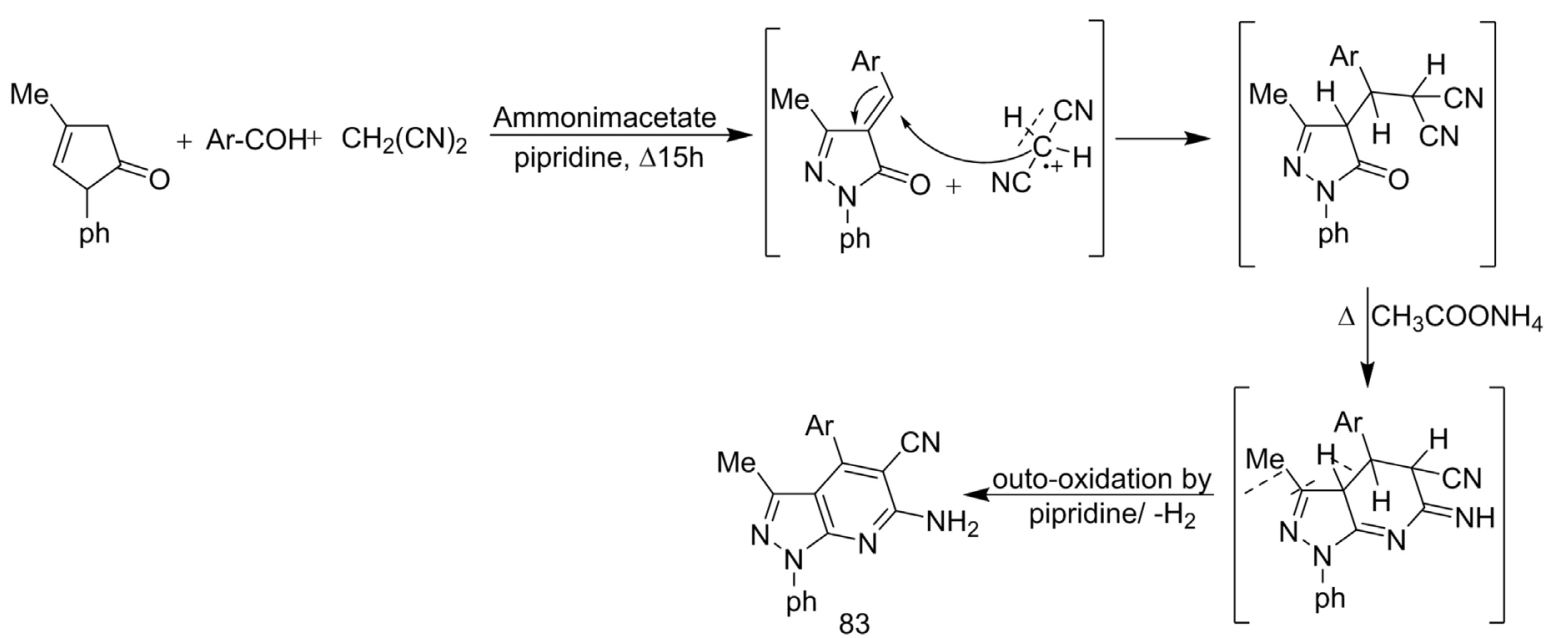

Scheme 35. Formation of 83 from edaravone 1. 

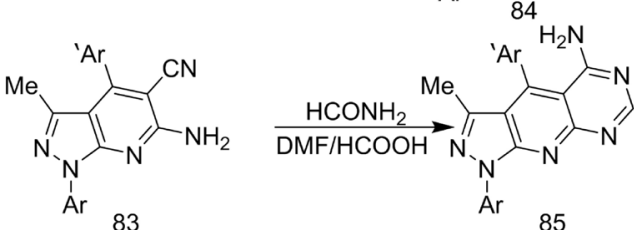

$\mathrm{Ar}=2,4-\left(\mathrm{NO}_{2}\right) \mathrm{C}_{6} \mathrm{H}_{3}$ $A r^{\prime}=4-\left(\mathrm{CH}_{3} \mathrm{O}\right) \mathrm{C}_{6} \mathrm{H}_{4}$


Scheme 36. Treatment of 83 with polyfunctional reagents.

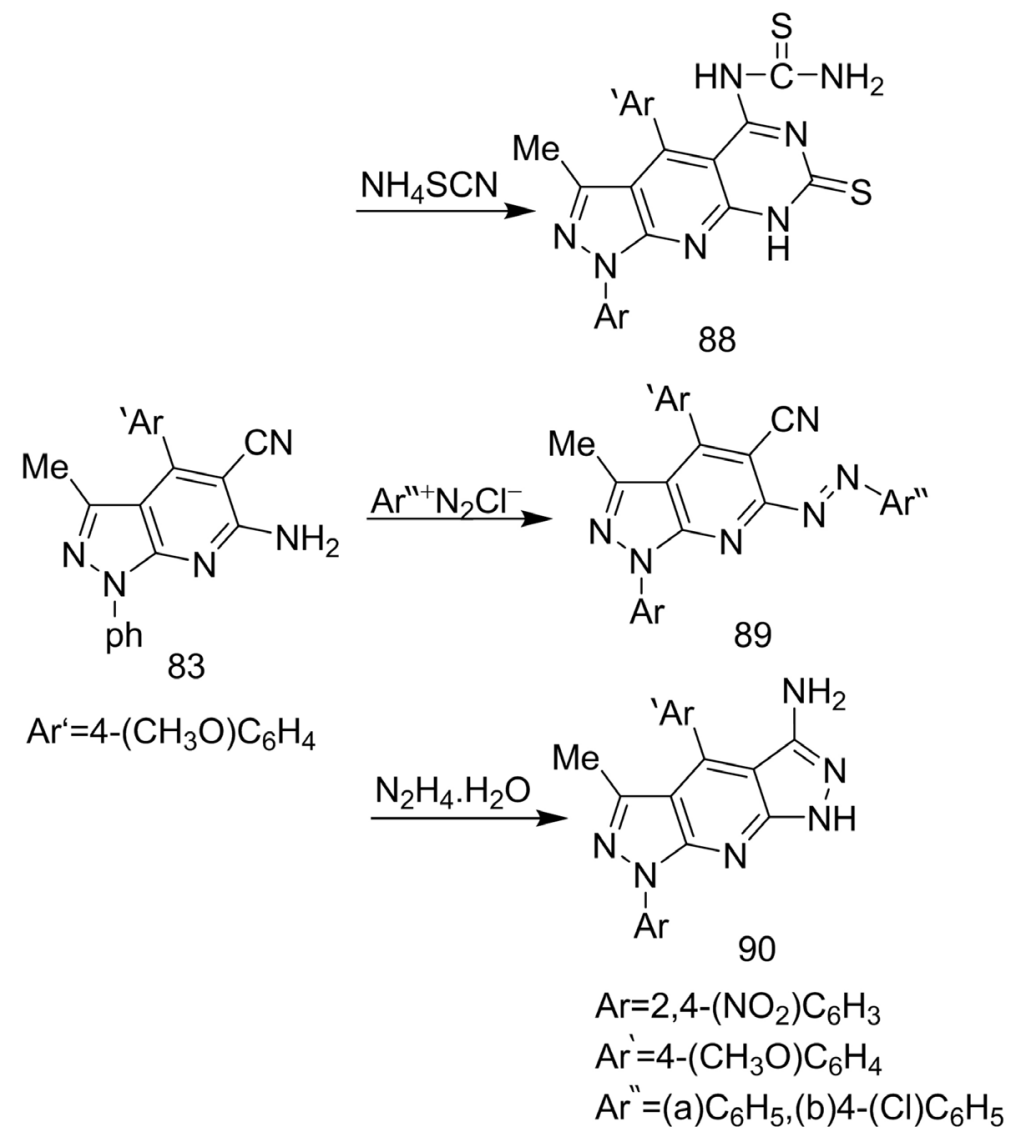

Scheme 37. Formation of $\mathbf{8 8}$ - 90 from 83.

\section{Conclusions}

Poly functional heterocyclic nitrogen systems as pyrazole, pyridine, and pyrimidine systems play a vital role in our life due to their biological, pharmacological, and medicinal properties [67] [68] [69] [70].

Based upon these important observations, this overview combines and reports 
the important attempts to obtain novel small units of heterocyclic systems in view of their biological evaluation which benefits the chemists and scientific researches in the future, from 2000 to $2020 \mathrm{AD}$.

\section{Conflicts of Interest}

The authors declare no conflicts of interest regarding the publication of this paper.

\section{References}

[1] Chellat, M.F., Raguž, L. and Riedl, R. (2016) Targeting Antibiotic Resistance. Angewandte Chemie International Edition, 55, 6600-6626. https://doi.org/10.1002/anie.201506818

[2] Dinoiu, V.J.L. (2006) Synthesis of New Trifluoromethyl-Containing 1-(3,5-Dialkyl-4hydroxybenzyl)-pyrazole and -pyrazol-5-one Derivatives and Their Corresponding Aroxyls Pyrazole. Journal of Serbian Chemical Society, 71, 323. https://doi.org/10.2298/JSC0604323D

[3] Hanamoto, T., et al. (2007) N-Arylation of 4-Fluoro-5-trimethylsilyl-1H-pyrazole. Journal of Fluorine Chemistry, 128, 1126-1130. https://doi.org/10.1016/j.jfluchem.2007.04.019

[4] Chaudhry, F., et al. (2013) Synthesis of Pyrazoleacrylic Acids and Their Derivatives. Asian Journal of Chemistry, 25, 7879-7882. https://doi.org/10.14233/ajchem.2013.14670

[5] Abdel-Rahman, R.M., Angawi, R.F. and Al-Mehmadi, A.R. (2017) Synthesis and Biological Evaluation of Fluorine Substuted Pyrazolo[4,3-e][1,2,4]triazines as Purine Analoguesi. Chemical Society, 21, 495-503. https://doi.org/10.1016/j.jscs.2016.11.004

[6] Bakhotmah, D. and Abdel-Rahman, R. (2016) A Review on the Synthesis and Chemistry of Bioactive Pyrazolines Bearing 1,2,4-Triazine Moieties. Mini-Reviews in Organic Chemistry, 13, 62-77. https://doi.org/10.2174/1570193X13666160225000114

[7] McDermott, L.A., et al. (2006) Biological Evaluation of a Multi-Targeted Small Molecule Inhibitor of Tumor-Induced Angiogenesis. Bioorganic \& Medicinal Chemistry Letters, 16, 1950-1953. https://doi.org/10.1016/j.bmcl.2005.12.092

[8] Bakhotmah, D.A., et al. (2017) Synthesis of Some New Fluorinated Fused Heteropolycyclic Nitrogen Systems Containing Pyrazolo[3,4-d]pyrimidines Moiety and Their Effects on Cellobiase Activity Produced by Aspergillus nidulans Fungi. Modern Organic Chemistry Research, 2, 172. https://doi.org/10.22606/mocr.2017.24003

[9] Khan, S.A., et al. (2017) Multistep Synthesis of Fluorine-Substituted Pyrazolopyrimidine Derivatives with Higher Antibacterial Efficacy Based on in Vitro Molecular Docking and Density Functional Theory. Journal of Heterocyclic Chemistry, 54, 3099-3107. https://doi.org/10.1002/jhet.2923

[10] Bräutigam, S., et al. (2009) Whole-Cell Biocatalysis: Evaluation of New Hydrophobic Ionic Liquids for Efficient Asymmetric Reduction of Prochiral Ketones. Enzyme and Microbial Technology, 45, 310-316. https://doi.org/10.1016/j.enzmictec.2009.06.015

[11] Watanabe, T., et al. (1994.) Protective Effects of MCI-186 on Cerebral Ischemia: Possible Involvement of Free Radical Scavenging and Antioxidant Actions. Journal 
of Pharmacology and Experimental Therapeutics, 268, 1597-1604.

[12] Li, Y.-J., et al. (2015) Evaluation of Sample Preparation and Chromatographic Separation for the Parallel Determination of Taurine and Edaravone in Rat Tissues Using HILIC-MS/MS. Analytical and Bioanalytical Chemistry, 407, 4143-4153. https://doi.org/10.1007/s00216-015-8635-0

[13] Holzer, W., et al. (2004) On the Tautomerism of Pyrazolones: The Geminal 2J[pyrazole C-4,H-3(5)] Spin Coupling Constant as a Diagnostic Tool. Tetrahedron, 60, 6791-6805. https://doi.org/10.1016/j.tet.2004.06.039

[14] Belmar, J., et al. (2005) Synthesis and Tautomeric Studies of Enamines from 1-(N-hexyl)-3-methyl-2-pyrazolin-5-one. Journal of the Brazilian Chemical Society, 16, 179-189. https://doi.org/10.1590/S0103-50532005000200009

[15] Abdul-Rahman, R.M., Bakhotmah, D. and Fakhorji, M. (2017) Synthesis and Chemical Reactivity of Some New Fluorine Substituted Pyrazolopyrimidine Derivatives and Their Effect on Cellobiase Activity Produced by Fungi. World Journal of Organic Chemistry, 5, 1-5.

[16] Abdel-Aziz, S. (1996) Fused Cyanopyrimidines: Part-I Synthesis and Reactions of Fused Cyanopyrimidine Derivatives and Their Effect on Cellobiase Activity. Phosphorus, Sulfur, and Silicon and the Related Elements, 116, 39-48. https://doi.org/10.1080/10426509608040467

[17] Abdel-Hamide, S., et al. (1995) Synthesis of Some New Piperazine-nn'-bis-substituted Derivatives as Potential Biologically Active Agents. Chemical Papers, 49, 142-148.

[18] Abdel-Rahman, R.M., et al. (2013) 1,2,4-Triazine Chemistry Part III: Synthetic Strategies to Functionalized Bridgehead Nitrogen Heteroannulated 1,2,4-Triazine Systems and Their Regiospecific and Pharmacological Properties. Current Organic Synthesis, 10, 136-160. https://doi.org/10.2174/157017913804810933

[19] Bakhotmah, D. and Abdel-Rahman, R. (2017) Synthesis and Structural Determination of Novel Fluorinated Steroidal Spiro (Pyrazolo[4,3-e][1,2,4]Triazin-3'-yl) Derivatives as Affecting Enzymatic Agents. Letters in Organic Chemistry, 14, 134-140. https://doi.org/10.2174/1570178614666161230143228

[20] Abdel-Rahman, R.M., Makki, M.S. and Al-Romaizan, A.N. (2014) Synthesis of Novel Fluorine Substituted Isolated and Fused Heterobicyclic Nitrogen Systems Bearing 6-(2'-Phosphorylanilido)-1,2,4-triazin-5-one Moiety as Potential Inhibitor towards HIV-1 Activity. International Journal of Organic Chemistry, 4, 247. https://doi.org/10.4236/ijoc.2014.44028

[21] Abdelhamid, A.O., et al. (2005) Reactions of Hydrazonoyl Halides 41: Synthesis of 1,2,4-Triazoles, 2,3-Dihydro-1,3,4-thiadiazoles and Triazolo[4,3-a]pyrimidines. Phosphorus, Sulfur, and Silicon and the Related Elements, 180, 2097-2109. https://doi.org/10.1080/104265090917448

[22] Bhardwaj, P. and Gupta, N. (2016) 1,2,4,5-Tetrazines as Platform Molecules for Energetic Materials and Pharmaceuticals. Iranian Journal of Organic Chemistry, 8 , 1827-1831.

[23] Bakhotmah, D.A. (2019) Synthesis of Fluorine and Phosphorus Compounds Bearing an Amino Pyrimidine-Substituted Pyrazolo[3,4-d]pyrimidine Moiety as Molluscicidal Agents against Some Snails. Polycyclic Aromatic Compounds, 1-9. https://doi.org/10.1080/10406638.2019.1684326

[24] Abdel-Rahman, R.M., et al. (2010) 1,2,4-Triazine Chemistry Part I: Orientation of Cyclization Reactions of Functionalized 1,2,4-Triazine Derivatives. European Journal of Chemistry, 1, 236-245. https://doi.org/10.5155/eurjchem.1.3.236-245.54

[25] Al-Hazme, B.D.A. and Al-Hazme, S.Y. (2019) Synthesis of Novel Heteropolycyclic 
Nitrogen Systems Bearing Fluorine Substituted Pyrazolo[3,4-d]pyrimidine Derived from Polyfunctional $\pi$-Acceptor Compounds and Guanidine as Fungicidal Probes. International Journal of Organic Chemistry, 9, 73-83. https://doi.org/10.4236/ijoc.2019.91007

[26] Makki, M.S., Abdel-Rahman, R.M. and Alharbi, A.S. (2018) Synthetic Approach for Novel Fluorine Substituted $\alpha$-Aminophosphonic Acids Containing 1,2,4-Triazin-5-one Moiety as Antioxidant Agents. International Journal of Organic Chemistry, 8, 1. https://doi.org/10.4236/ijoc.2018.81001

[27] Makki, M.S., et al. (2012.) Designing and Synthesis of New fluorine Substituted Pyrimidine-thion-5-carbonitriles and the Related Derivatives as Photochemical Probe Agents for Inhibition of Vitiligo Disease. International Journal of Organic Chemistry, 2, 311. https://doi.org/10.4236/ijoc.2012.223043

[28] Taib, L.A. and Adibani, S.A. (2018) Synthesis of New Fluorinated Fused Heteropolycyclic Nitrogen Systems Containing a Pyrazolotriazine Moiety as Antimicrobial Agents Part I. International Journal of Organic Chemistry, 8, 176. https://doi.org/10.4236/ijoc.2018.81013

[29] Bawazir, W.A. and Abdel-Rahman, R.M. (2018) Synthesis of New Fluorinated Amino-Heterocyclic Compounds Bearing 6-Aryl-5-oxo-1,2,4-triazin-3-yl Moiety as Antimicrobial Agents. International Journal of Organic Chemistry, 8, 349. https://doi.org/10.4236/ijoc.2018.84027

[30] Makki, M.S., Abdel-Rahman, R.M. and Alharbi, A.S. (2019) Synthesis and Anti-Inflammatory Effect of Some More New Fluorinated 3-Substituted Amino/3,5-Diamino-1,2,4-triazine Derivatives as Lamotrigine Analogs. Current Organic Synthesis, 16, 165-172. https://doi.org/10.2174/1570179415666181105142247

[31] Bakhotmah, D.A. and Al-Hazme, S.Y. (2019) Behavior of 6-Amino-4(4'-fluorophenyl)-1phenyl-3-methyl Pyrazolo[3,4-d]pyrimidine towards $\pi$-Acceptors Activated Carbonitrile and Carbonyl Compounds as Amylolytic Agents towards Some Fungi.

[32] Al-Najjar, A.A., Amer, S.A., Riad, M., Elghamy, I. and Elnagdi, M.H. (1996) Studies with Polyfunctionally Substituted Heteroaromatic. A Routes for the Synthesis of Substituted 1,2,4-Triazolo[1,5-a]pyridines. Journal of Chemical Research, 296-297.

[33] Abdel-Monem, W. (2004) Synthesis and Biological Evaluation of Some New Fused Heterobicyclic Derivatives Containing 1,2,4-Triazolo/1,2,4-Triazinopyridinone Moieties. Chemical Papers-Slovak Academy of Sciences, 58, 276-285.

https://doi.org/10.1002/chin.200515138

[34] Abdel-Monem, W.R. and Abdel-Rahman, R.M. (2005) 3-Dichloro/Dioxo Pyrido[1,2-b][1,2,4] triazine Derivatives towards Bi-Primary Nitrogen Agents and Their Biocidal Effects. Bollettino Chimico Farmaceutico, 144, 1-12.

[35] Ibrahim, M.A., et al. (2009) Synthesis, Chemical Reactivity and Fungicidal Activity of Pyrido[1,2-b][1,2,4]triazine Derivatives. Journal of the Brazilian Chemical Society, 20, 1275-1286. https://doi.org/10.1590/S0103-50532009000700012

[36] Ibrahim, M.A., et al. (2008) Synthesis and Antifungal Activity of Novel Polyheterocyclic Compounds Containing Fused 1,2,4-Triazine Moiety. Arkivoc, 16, 202-215. https://doi.org/10.3998/ark.5550190.0009.g19

[37] Komarova, E., et al. (2007) 4,5-Diamino-1-phenyl-1,7-dihydro-6H-pyrazolo[3,4-b] pyridin-6-one in the Synthesis of Fused Tricyclic Systems. Russian Chemical Bulletin, 56, 2337-2343. https://doi.org/10.1007/s11172-007-0369-5

[38] Katharkar, S.A. and Shinde, D.B. (2006) Synthesis of Antimicrobial 2,9,10Trisubstitutcd-6-oxo-7,12-dihydro-chromcno[3,4-b]quinoxalines. Bioorganic \& 
Medicinal Chemistry Letters, 16, 6181-6184. https://doi.org/10.1016/j.bmcl.2006.09.040

[39] Zhang, G. and Chen, J. (2011) Synthesis and Cytotoxic Activities of 2-(4-(2Heterocycloethoxy)phenyl)-1,2,4-triazolo[1,5-a]pyridines. Letters in Organic Chemistry, 8, 180-183. https://doi.org/10.2174/157017811795038377

[40] Riedl, Z., et al. (2003) Ring Opening and Cycloadditions of Novel Fused 1,2,4-Triazines. Arkivoc, 62, 68. https://doi.org/10.3998/ark.5550190.0004.506

[41] Rashad, A.E., et al. (2010) Synthesis, Reactions and Antimicrobial Evaluation of Some Polycondensed Thienopyrimidine Derivatives. Synthetic Communications, 40, 1149-1160. https://doi.org/10.1080/00397910903050954

[42] Ali, T.E.-S. and Ibrahim, M.A. (2010) Synthesis and Antimicrobial Activity of Chromone-Linked 2-Pyridone Fused with 1,2,4-Triazoles, 1,2,4-Triazines and 1,2,4-Triazepines Ring Systems. Journal of the Brazilian Chemical Society, 21, 1007-1016. https://doi.org/10.1590/S0103-50532010000600010

[43] Abdel-Megid, M. (2009) Synthesis of Some New Nitrogen Bridge-Head Pyrido[1,2,4] triazepines. Chemistry of Heterocyclic Compounds, 45, 1523-1531. https://doi.org/10.1007/s10593-010-0460-y

[44] El-Kazak, A.M. and Ibrahim, M.A. (2013) Synthesis, Characterization and Antimicrobial Evaluation of the Novel Pyrido[1',2':2,3][1,2,4]triazolo[1,5-c]quinazolines and Thiazolo[3',2':2,3][1,2,4]triazolo[1,5-a]pyridines. ARKIVOC Online Journal of Organic Chemistry, 3, 282-293. https://doi.org/10.3998/ark.5550190.p007.884

[45] Harb, A., Abbas, H. and Mostafa, F. (2005) Pyrazoles as Building Blocks in Heterocyclic Synthesis: Synthesis of Some New Substituted 1-Triazinylpyrazolo [3,4-d] pyrimidine and 1-Triazinylpyrazolo[3,4-b]pyridine Derivatives. Chemical Papers-Slovak Academy of Sciences, 59, 187. https://doi.org/10.1002/chin.200550154

[46] Abdel-Rahman, R.M., et al. (2015) 1,2,4-Triazine Chemistry Part IV: Synthesis and Chemical Behavior of 3-Functionalized 5,6-Diphenyl-1,2,4-triazines towards Some Nucleophilic and Electrophilic Reagents. Journal of Heterocyclic Chemistry, 52, 1595-1607. https://doi.org/10.1002/jhet.2014

[47] Elguero, J., et al. (2002) Pyrazoles as Drugs: Facts and Fantasies. Targets in Heterocyclic Systems, 6, 52-98.

[48] Quiroga, J., et al. (2008) Regioselective Formylation of Pyrazolo[3,4-b]pyridine and Pyrazolo[1,5-a]pyrimidine Systems Using Vilsmeier-Haack Conditions. Tetrahedron Letters, 49, 2689-2691. https://doi.org/10.1016/j.tetlet.2008.02.166

[49] Darwish, E.S., Mahmoud, F.F. and Farag, M. (2012) Synthesis and Antimicrobial Evaluation of Some New Pyrazole, Fused Pyrazolo[1,5-a]-pyrimidine and Pyrazolo[1,5-d]pyrimido[4,5-d]][1,2,3]triazine Derivatives. Asian Journal of Chemistry, 24, 2997.

[50] Quiroga, J., et al. (2001) Synthesis and Structural Analysis of 5-Cyanodihydropyrazolo [3,4-b]pyridines. Journal of Heterocyclic Chemistry, 38, 53-60. https://doi.org/10.1002/jhet.5570380108

[51] Hardy, C. (1984) The Chemistry of Pyrazolopyridines in Advances in Heterocyclic Chemistry. Elsevier, Amsterdam, 343-409.

https://doi.org/10.1016/S0065-2725(08)60117-8

[52] Wertalik, F. and Bonorden, R. (1968) Salivary Levels of Antibiotics from Use of Neomycin-Gramicidin Chewing Troches. Journal of Pharmaceutical Sciences, 57, 530-531. https://doi.org/10.1002/jps.2600570340 
[53] Elnagdi, M.H. and Wahba, E.A. (1990) Synthesis of Substituted Azaindenes: Synthesis of New Pyrazolo[1,5-a]pyrimidine Derivatives. Bulletin of the Chemical Society of Japan, 63, 1854-1856. https://doi.org/10.1246/bcsj.63.1854

[54] Chavhan, N., et al. (2010) Synthesis and Biological Evaluation of Some Heterocycles from 1-Phenyl-3-(pyridine-3-yl)-1H-pyrazole-4-carbaldehyde. Asian Journal of Chemistry, 22, 4255.

[55] Straub, A., et al. (2001) NO-Independent Stimulators of Soluble Guanylate Cyclase. Bioorganic \& Medicinal Chemistry Letters, 11, 781. https://www.ncbi.nlm.nih.gov/pubmed/11277519

[56] Elnagdi, M.H., Elmoghayar, M.R.H. and Elgemeie, G.E.H. (1987) Chemistry of Pyrazolopyrimidines. In: Advances in Heterocyclic Chemistry, Elsevier, Amsterdam, 319-376. https://doi.org/10.1016/S0065-2725(08)60164-6

[57] Sekikawa, I., et al. (1973) Antituberculous Compounds; Synthesis of Pyrazolopyridines. Journal of Heterocyclic Chemistry, 10, 931-932. https://doi.org/10.1002/jhet.5570100607

[58] Kuczyński, L., et al. (1979) Synthesis and Biological Activity of Pyrazo-[3,4-b]-pyridine Derivatives. Part I. Polish Journal of Pharmacology and Pharmacy, 31, 217-225.

[59] Zeitschrift für El-Dean, A.K., et al. (1991) Synthesis of Some Pyrazolopyridine Sulphonamide Derivatives. Naturforschung B, 46, 541-546. https://doi.org/10.1515/znb-1991-0417

[60] Chioua, M., et al. (2009) Synthesis and Biological Evaluation of 3,6-Diamino-1Hpyrazolo[3,4-b]pyridine Derivatives as Protein Kinase Inhibitors. Bioorganic \& $\mathrm{Me}$ dicinal Chemistry Letters, 19, 4566-4569. https://doi.org/10.1016/j.bmcl.2009.06.099

[61] Dias, L.R., et al. (2007) Synthesis, in Vitro Evaluation, and SAR Studies of a Potential Antichagasic 1H-pyrazolo[3,4-b]pyridine Series. Bioorganic \& Medicinal Chemistry, 15, 211-219. https://doi.org/10.1016/j.bmc.2006.09.067

[62] Chebanov, V.A., et al. (2007) Cyclocondensation Reactions of 5-Aminopyrazoles, Pyruvic Acids and Aldehydes. Multicomponent Approaches to Pyrazolopyridines and Related Products. Tetrahedron, 63, 1229-1242. https://doi.org/10.1016/j.tet.2006.11.048

[63] Lynch, B.M., et al. (1988) Pyrazolo[3,4-b]pyridines: Syntheses, Reactions, and Nuclear Magnetic Resonance Spectra. Canadian Journal of Chemistry, 66, 420-428. https://doi.org/10.1139/v88-074

[64] Tensmeyer, L. and Ainsworth, C. (1966) Proton Magnetic Resonance Studies of Pyrazoles. The Journal of Organic Chemistry, 31, 1878-1883.

https://doi.org/10.1021/jo01344a047

[65] Maqbool, T., et al. (2013) Pyrazolopyridines I: Synthesis of Some Pyrazolo[3,4-b]pyridine-4-carboxylates. Asian Journal of Chemistry, 25, 7715-7718. https://doi.org/10.14233/ajchem.2013.14573A

[66] El-Assiery, S.A., Sayed, G.H. and Fouda, A. (2004.) Synthesis of Some New Annulated Pyrazolo-Pyrido (or Pyrano) Pyrimidine, Pyrazolopyridine and Pyranopyrazole Derivatives. Acta Pharmaceutica (Zagreb), 54, 143-150.

[67] El-Emary, T.I. (2007) Synthesis of Newly Substituted Pyrazoles and Substituted Pyrazolo[3,4-b]pyridines Based on 5-Amino-3-methyl-1-phenylpyrazole. Journal of the Chinese Chemical Society, 54, 507-518. https://doi.org/10.1002/jccs.200700072

[68] Acosta, P., et al. (2015) Annelation of Pyrrolo[1,2-a]pyrimidine and Pyrido[1,2-a]pyrimidine Systems to a Pyrazolopyridine Framework by a Cascade of Two Cyclization Reactions. Tetrahedron Letters, 56, 2917-2921. 
https://doi.org/10.1016/j.tetlet.2015.04.068

[69] Quiroga, J., et al. (2015) Synthesis and Study of Fluorescence Properties of Novel Pyrazolo[4',3':5,6]pyrido[2,3-d]pyrimidin-5(6H)-one Derivatives. Journal of Molecular Structure, 1097, 69-75. https://doi.org/10.1016/j.molstruc.2015.05.019

[70] Acosta, P., et al. (2017) Synthesis of Novel 7-Aryl and 7-Spiropyrazolo [4',3':5,6]pyrido[2,3-d]pyrimidine Derivatives and Their Study as AChE Inhibitors. Molecular Diversity, 21, 943-955. https://doi.org/10.1007/s11030-017-9774-3 